\title{
Mulas em movimento: o mercado interno brasileiro e o negócio de tropas, primeira metade do século XIX
}

Luiz Adriano Borges*

Resumo: O objetivo deste trabalho é analisar o negócio de muares brasileiro e como este se desenvolveu em ligação com as regiões da América Espanhola. Assim, empreendo o estudo da trajetória de um dos maiores negociantes de muares do sul do Brasil no século XIX, João da Silva Machado. Este indivíduo empreendeu diversas viagens à região sul do Brasil e à Buenos Aires e Montevidéu, buscando comprar os melhores animais para serem revendidos em uma feira em São Paulo. Assim, analiso a relação do mercado interno que se estendia desde lado espanhol até o brasileiro - no espaço econômico que ligava estes dois mercados através do negócio de muares. Utilizo para tanto os Registros de Passagem de Animais do Registro de Curitiba, entre os anos de 1824 e 1829, importante marca na ascensão do mercado interno de animais. Estes registros, que serviam como um espécie de pedágio, traziam anotados todos os animais passados por essa localidade e sua origem. Portanto, uma ótima fonte para se perceber os fluxos do negócio de animais no sul e, inclusive, sua relação com o lado espanhol.

Palavras-chave: Negócio de animais. Mercado interno. Transporte.

João da Silva Machado foi um dos maiores negociantes de animais do sul do Brasil no século XIX. Nasceu em 1782, em uma região fortemente voltada à criação e comercialização de animais, Taquari, próxima a Viamão. Nesta região se iniciava uma importante

"Doutor em História pela Universidade Federal do Paraná - UFPR. Professor da Universidade Tecnológica Federal do Paraná - UTFPR-Toledo. E-mail: luizborges@utfpr.edu.br

Anos 90, Porto Alegre, v. 23, n. 44, p. 207-230, dez. 2016 
rota de tropeiros, no atual Rio Grande do Sul. A data de nascimento de Machado marca o início de um espantoso aumento do negócio de animais, que tende a permanecer dinâmico até meados do século XIX. A área em que ele nasceu possuía fortes ligações com a América espanhola, de onde eram importados animais e técnicas. Aparentemente, este negociante chegou a viajar até o Uruguai e Argentina, procurando obter muares com o máximo possível de lucro. Há relatos de uma viagem dele à Buenos Aires, por volta da década de 1830, para procurar documentos referentes a aldeamentos jesuíticos, o que faz pensar que ele já conhecia aquele país (MACHADO, 1885, p. 109-117).

Assim, estudar a trajetória econômica deste indivíduo, focando em seu negócio de muares, possibilita compreender esta atividade "por dentro", além de permitir entender um pouco mais o funcionamento do mercado interno, que tendia a ultrapassar as fronteiras coloniais. Foi utilizada para este texto a documentação dos Registros de passagem de animais do registro de Curitiba, para o período de 1824 a 1829. Esta fonte, fruto de uma espécie de pedágio onde todos os animais eram taxados, permite perceber a movimentação das tropas de mulas vindas do sul e também nos aponta a relação com o comércio do lado espanhol. E mais, no que concerne à estes documentos, esse período ainda não foi analisado devidamente e, portanto, seu exame revela alguns fatores pertinentes para este comércio.

Assim, aqui se pretende um esforço de análise comparada, para demonstrar semelhanças e diferenças e, sobretudo, ligações entre locais coloniais com diferente administração.

Nestas regiões que conhecemos hoje como México, Peru, Argentina, Uruguai e Brasil, a mula foi a principal forma de transporte no período colonial. No caso brasileiro, vários tipos de animais, destinados a variadas funções, eram trazidos das pradarias do Rio Grande do Sul. Principalmente as mulas foram a força motriz do sistema de transporte para o escoamento da produção interna de várias regiões e períodos no Brasil: o ouro das Minas Gerais, o açúcar e o café de São Paulo e do Rio de Janeiro. A imensidão de animais negociados chega a 1.498 milhão de muares que passaram pela feira de Sorocaba, entre os anos de 1825 a 1880 (KLEIN, 1989, p. 356)1. 
A mula é um animal híbrido, que resulta do cruzamento de um burro com uma égua, que possuí uma mescla de características: robusto e resistente, herança do burro, com um porte maior, legado da espécie dos cavalos (HAMEISTER, 2002, p. 75).

Portanto, este híbrido se mostrava uma ótima opção para enfrentar os caminhos coloniais: era estável nas trilhas pedregosas, resistentes às variações climáticas e às alturas. Em longas distâncias era mais resistente e mais rápido que os cavalos (PRIORE; VENANCIO, 2006, p. 75). Eram mais robustas e com costas mais planas que estes. Enquanto cavalos não carregavam mais que 115 quilos, as mulas podiam carregar de 135 a 225 quilos. Elas requeriam menos alimento e possuíam grande desempenho (BARMAN, 2000, p. 143). Cálculos para a América Espanhola apontam que uma mula, em tropa, cavalgava a $6 \mathrm{~km}$ por hora, chegando a percorrer $60 \mathrm{~km}$ de distância de uma vez, em um dia (BARSKY; DJENDEREDJIAN, 2003, p. 240). No Brasil, talvez por ter territórios um pouco menos acidentados, estimula-se que uma mula totalmente carregada, fazendo parte de uma tropa, podia viajar entre 3 e 4 léguas (GOULART, 1961, p. 102), ou entre 13 e $17 \mathrm{~km}$ (KLEIN, 1989, p. 364). Era, portanto, um animal adequado para o transporte de cargas pesadas. Mas por ser estéril, a dificuldade para sua reprodução elevava o valor final.

Como indica Martha Hameister, o cruzamento de animais para o surgimento da mula começou a ocorrer no Rio Grande do Sul por volta da década de 1750 . Antes disso, os muares vinham do lado espanhol da América, que começou sua criação na região de Salta, Tucumã, Santa Fé, Córdoba e Buenos Aires, impulsionados pela atividade mineira de prata de Potosí, no Alto-Peru (HAMEISTER, 2002, p. 224; GARAVAGLIA, 1999, p. 217). Destas regiões, foram contrabandeados animais e importadas técnicas.

$\mathrm{Na}$ colônia portuguesa, de maneira semelhante à América espanhola, o fator que fez impulsionar a utilização deste animal como principal meio de transporte de mercadorias foi a descoberta de ouro na região de Goiás e das Minas Gerais. Hameister diz que foi a "[...] voraz necessidade de meios de transporte e tração de cargas para os produtos coloniais [...]" da região das Minas que "[...] financiou a consolidação do extremo-sul" (HAMEISTER, 2002, p. 18), que até o século XVII possuía uma escassa população. 
A abertura das minas em Goiás levou o Capitão-general de São Paulo a mandar abrir, ainda em 1730, uma estrada que ligasse as Vacarias da Serra aos Campos de Curitiba, para trazer gado para as Minas, já que surgiram problemas de abastecimento naquelas regiões (BALHANA, 1969, p. 95). A feira de Sorocaba, onde os animais eram comprados e vendidos, foi criada por esta época, sistematizando o comércio e articulando a ligação com as regiões mineradoras. $\mathrm{O}$ próprio crescimento populacional destas regiões incentivou o fornecimento de gêneros, criando uma incipiente movimentação de mercadorias desde São Paulo e das regiões do Sul. O gado muar foi fundamental tanto para o escoamento do ouro das minas para os portos como para a condução de alimentos até as regiões mineradoras.

\section{Mercado interno - ligações regionais}

As técnicas para a criação eram compartilhadas e os animais comercializados ou contrabandeados das regiões da América Espanhola. Helen Osório chega a afirmar que os domínios espanhóis e portugueses nos limites sulinos possuíam uma estrutura produtiva similar, compondo uma mesma paisagem agrária, e formavam um continuum desde Buenos Aires a Banda Oriental do rio Uruguai (atual Uruguai) até o atual Rio Grande do Sul (OSÓRIO, 2007, p. 39). Esta ligação era evidenciada pelas rotas comerciais que se formavam desde Santa Fé (hoje na Argentina) e Minas Gerais desde o século XVIII (GIL, 2002). Por volta de 1810 o Uruguai possuía pelo menos um milhão e meio de cabeças de gado selvagem (BARRIOS PINTO, 1971, apud CHRISTILLINO, 2010, p. 78), o que evidencia a importância da região platina para o comércio de animais.

Em se tratando de criação, o gado brasileiro (tanto vacum quanto muar) é uma mistura de várias raças e técnicas presentes nas fronteiras das colônias ibéricas. Segundo Roberto Simonsen, além da altitude e da boa qualidade das pastagens, a geografia econômica favoreceu as regiões sulinas no desenvolvimento do gado bovino de corte e muar onde, misturando-se raças, buscou-se um aprimoramento dos espécimes (SIMONSEN, 2005, p. 215). 
Pesquisadores uruguaios e principalmente argentinos têm escrito bastante sobre as relações de mercado interno entre os sul-americanos. Miguel A. Rosal e Roberto Schmit indicam que

[...] na região do Rio da Prata, desde os tempos tardocolonais, foi possível um incremento da produção rural graças à abundância de terras aptas para a pecuária extensiva, $\mathrm{o}$ clima temperado e com suficientes chuvas, o rápido acesso às vias fluviais que barateavam o transporte, as medidas alfandegárias tendentes a reduzir os impostos coloniais, especialmente das exportações, e as poucas melhoras técnicas necessárias para o funcionamento do setor (ROSAL; SCHMIT, 2004, p. 187).

Os pampas meridionais possuem uma vegetação típica de pradarias, que é um ecossistema desprovido quase completamente de árvores e coberto por uma formação baixa, onde dominam as gramíneas (GARAVAGLIA, 1999, p. 17). Assim, o tipo de solo e a vegetação dos pampas da região do Rio da Prata favoreciam muito a pecuária.

Também a privilegiada localização de Buenos Aires, com acesso facilitado ao continente americano através do Rio da Prata, ajudou a convertê-la no núcleo urbano onde os comerciantes importadores e exportadores de metais preciosos - provenientes do Alto Peru acumularam significativas fortunas durante o século XVIII e início do século XIX. Mas é a partir da segunda metade do século XVIII que alguns destes comerciantes que fizeram fortuna começaram a adquirir campos na Banda Oriental e Entre Rios, formando-se ali grandes estâncias cujos produtos pecuários começaram a se destacar entre as exportações rio-platenses.

A criação de animais vacuns e muares em Buenos Aires foi impulsionada pela descoberta de prata nas minas de Potosí, no Alto Peru. A distância entre Buenos Aires até Salta e Jujuy, locais de tradicionais feiras de venda de gado, era de cerca de $2200 \mathrm{~km}$ (para efeitos de comparação, dentro do território português, o Caminho dos Tropeiros, de Viamão até a feira de Sorocaba era metade disto, em torno de $1100 \mathrm{~km}$ ). Dali, os animais eram reenviados até as minas 
peruanas. Em Buenos Aires, Entre Rios e Banda Oriental, desde os fins do século XVIII, o gado vacum foi o animal predominante nas estâncias. Em Buenos Aires, os muares tiveram importância até início da década de 1780 , a partir de então os vacuns crescem em importância.

$\mathrm{O}$ auge do comércio de mulas na feira de Salta coincide com o aumento da negociação de animais no sul do Brasil, graças às ampliações da demanda no centro-sul em virtude do ouro das Minas Gerais. Os anos de 1765 a 1779 marcaram o auge da passagem de mulas, com uma média de 33 mil animais por ano; depois de uma crise, a comercialização volta a crescer entre os anos de 1795 a 1808, com a passagem de 31 mil mulas anuais (PAZ, 1999, p. 48).

É interessante compreender a maneira como era criadas as mulas no lado espanhol para percebermos as influências na criação brasileira. Paz, baseado no viajante Carrio de La Vandera, relata que o funcionamento do sistema de criação e invernada de mulas se dava da seguinte maneira:

[...] as mulas nasciam e se criavam nos campos de Buenos Aires e ao sul de Santa Fé até completar 2 anos. Logo depois eram transportadas a Córdoba em tropas de 600 a 700 animais, e vendidos ali a invernadores e comerciantes [...]. Permaneciam nos potreiros de Córdoba de um ano a 14 meses para sua maturação. Depois deste tempo, as mulas eram conduzidas a Salta em número de 1300 a 1400 por tropa e, antes de chegar ali, paravam para uma segunda invernada de aproximadamente oito meses. As mulas deviam engordar para a grande feira anual em Salta (PAZ, 1999, p. 50 , tradução nossa).

Segundo Maria Victoria Marquez, os maiores comerciantes de mulas de Salta compravam propriedades e potreiros em zonas aptas para invernada e conjugava esta atividade com o comércio, o que lhes permitia evitar o pagamento a terceiros e, às vezes, lucrar com o serviço de invernada prestados a outros "muleiros" que não dispunham daquele recurso (MÁRQUEZ, 2008, p. 9). 
Marquez assinala que havia uma ligação entre o norte mineiro de Buenos Aires, as regiões de Santa Fé, Córdoba e o Brasil. Santa Fé, configurada como ponto intermediário nas diversas rotas que conectavam o interior, a zona das missões e o Paraguai com o Atlântico, se tornou no século XVIII um centro comercial e administrativo, sem deixar de ser cabeça de um vasto espaço de produção pecuária. Produtores que também atuavam às vezes como comerciantes, levavam para vender imensas "arrias" de mulas até Salta e Potosi. Pelo lado português, Tiago Gil também percebeu uma rota que ligava Santa Fé, Rio Grande do Sul, Sorocaba e Minas Gerais (MÁRQUEZ, 2008, p. 103).

Carlos Sempat Assadourian visualizou ligações entre as regiões espanholas e portuguesas desde muito cedo na colonização americana. Segundo o autor, a partir de 1590 a criação de gado em Córdoba cobriu as necessidades do seu comércio regional, se iniciando uma atividade exportadora dos excedentes, que se dirige para feiras em Potosí e no Brasil. Apesar de entrar em crise na década de 1620, um comércio insipiente se mantém entre essas regiões (ASSADOURIAN, 1982).

Em Córdoba, a criação de mulas vinha desde o século XVII e nos séculos seguintes seguiu enviando grande parte dos animais negociados na feira de Salta. Córdoba fazia parte da rota comercial colonial e se encontrava intensamente integrada à produção mineira do alto-peru. Como já havia apontado de maneira inicial por Assadourian, Sonia Tell diz que, desde 1630, Córdoba se tornou uma região especializada na cria e invernada de mulas e outros gados destinados principalmente a abastecer a demanda dos centros mineiros, especialmente a província de Charcas, na atual Bolívia. Segundo esta autora, "[...] até 1810 a exportação de mulas até estes centros mineradores esteve na base de todas as relações mercantis de Córdoba” (TELL, 2005, p. 93-96, tradução nossa). A partir de 1770, Córdoba também enviou gado em pé para o Chile, além do Paraguai e as outras economias regionais que formavam a antiga governação de Tucumán e que mais tarde conformariam o espaço econômico do interior argentino: Santiago Del Estero, Catamarca, La Rioja, Tucumán, Salta y Jujuy. 
Mas, a partir da segunda metade do século XVII a decadência da exportação de mulas foi notável, com a queda nos preços e nas exportações. É somente partir de 1740 , com um renascimento da produção mineira, que ocorreu uma reversão nas exportações de mulas.

A feira de Salta possuía características muito semelhantes com uma importante feira que surgiria no século XVIII em Sorocaba, no centro sul do Brasil: ambas funcionavam como redistribuidoras de animais e em seus auges, possuíam números comercializados semelhantes. No início do século XIX, na feira de Salta eram negociados entre 40.000 a 50.000 mulas, das quais 30.000 provinham de Córdoba ou eram criadas em Santa Fé, Buenos Aires e invernadas nas serras cordobesas. A decadência e posterior fim das vendas de mulas para a região mineradora encontram seu epicentro nos acontecimentos revolucionários de 1809 e a crise definitiva de 1814, quando os envios de mulas às feiras de Salta desaparecem completamente dos registros de Córdoba (TELL, 2005, p. 94).

A partir da Independência Argentina, em maio de 1810, decresce a exportação de mulas, mas antes mesmo disso as exportações de couro começaram a crescer e tomar conta da economia portenha. Como apontam Barsky e Djenderedjian, com a criação do Vice-reinado do Prata, em 1776 e o decreto de 1778 que autorizava o comércio com treze portos espanhóis, os couros e outros produtos agropecuários desequilibraram a balança comercial rioplatense (BARSKY; DJENDEREDJIAN, 2003, p. 144). A partir daí, os couros passaram a ser os principais produtos de exportação da Argentina, abandonando-se a criação de mulas quase que por completo. $\mathrm{O}$ caminho é deixado aberto para a expansão da criação de animais em solo brasileiro.

No lado espanhol, vizinha à Argentina ficava outra área de relevo na criação de animais, onde brasileiros iam buscar gado: a região que viria a ser o Uruguai. A relação dos criadores uruguaios com os brasileiros foi muito forte, inclusive estes últimos acabavam possuindo propriedades no lado espanhol do Rio da Prata. Aida Lavalle, analisando inventários de proprietários brasileiros no atual estado do Paraná, encontrou referências de posses no Uruguai (LAVALLE, 1974, p. 78). Vários condutores e/ou negociantes 
compravam animais originados na região espanhola. É o caso de David dos Santos Pacheco, um sócio de João da Silva Machado, que entre os anos de 1839 e 1840, viajou a Montevidéu para adquirir animais (WESTPHALEN, 1995, p. 54). José Joaquim de Lacerda, atuando muitas vezes como sócio do sorocabano Rafael Tobias de Aguiar, ia "anualmente ao Uruguai buscar tropas para revender Brasil afora” (CATELLI JR., 1993, p. 75 apud BADDINI, 2002, p. 125).

Colônia era uma das mais férteis regiões do Uruguai e com um solo abundante em pastos naturais, fazendo parte do pampa que engloba a região de Buenos Aires e Rio Grande do Sul (GELMAN, 1998).

A Colônia de Sacramento, no centro do território de Colônia, foi fundada por portugueses em 1680, vindo a causar muitos desentendimentos devido à sua localização que, de acordo com o Tratado de Tordesilhas, ficava em território espanhol. Segundo Maximiliano Menz,

[...] a fundação da Colônia de Sacramento deu início a uma corrida pelas posições no extremo-sul atlântico: além da própria Nova Colônia, Portugal fundou Laguna (1684) e Rio Grande (1737); já a Espanha abençoou a expansão jesuítica com os Sete Povos ao leste do Rio Uruguai (1682-1707) e estabeleceu Montevidéu (1734) na embocadura do Rio da Prata (MENZ, 2009, p. 36).

O estabelecimento de Colônia foi estratégico, já que nesta região abundava gado bravio solto. Para ampliar o comércio do Sul foi feito um caminho que unia os campos do Rio Grande à zona mineradora. Em 1727 Cristóvão Pereira de Abreu e Francisco de Souza Faria abriram o caminho que passou a ser muito importante na exportação de gado em pé: partindo da Colônia, as tropas invernavam nos campos ao redor do presídio de Rio Grande, passando pelo litoral para Laguna e daí, pelo caminho do Araranguá, paravam em Lages de onde seguiam sem grandes pausas até São Paulo. Lages e São Joaquim, hoje em território catarinense, possuíam pastos esplêndidos para os animais. Os campos de Curitiba, vila fundada em 1614, também ofereciam área muito boa para a invernada. Em 
1733, Cristóvão Pereira retocou a estrada e levou a primeira tropa do Sul a São Paulo, estabelecendo o conhecido Caminho dos Tropeiros ou do Viamão (SIMONSEN, 2005, p. 210-211; MENZ, 2009, p. 36). Na época em que nosso negociante, João da Silva Machado, atuava, esta estrada continuava com seu traçado original, sendo pouco alterada. O próprio Machado foi responsável por encurtá-la na década de 1820.

Raul Cheda relata a criação de mulas em Colonia do Sacramento:

[...] Don Francisco Pinto Villalobos, oficial de guerra de la Colonia, consiguió en 1751 de la Corte de Madrid, permiso para extraer mulas con destino a los dominios portugueses [...] Concedió el Gobernador de Buenos Aires un permiso para la extracción de 3800 mulas y más adelante lo extendió hasta permitir que fuera extraídas 6.000 [...] y esta extracción, no parece coyuntural, puesto que más adelante, la referencia indica que el Cabildo de Buenos Aires y el Gobernador de Tucumán consideraron que esta última extracción iba a provocar el alza de los precios en la comercialización interna, reforzando la hipótesis del envío periódico de mulas orientales hacia el mercado de Tucumán, al menos desde la zona de Colonia (CHEDA, 2005, p. 16).

Aliás, Tucumán também fez parte do comércio regional que ia de Buenos Aires até o alto Peru, graças também a sua localização. Essa região ingressou no circuito da prata através da produção de gado e seus derivados, que eram comercializados pelos vizinhos nas feiras peruanas. Além disso, Tucuman vinculou-se ao circuito de contrabando que se praticava no Brasil e ingressava por Buenos Aires (ALBORNOZ, 2002, p. 4).

Assim, na primeira metade do século XVIII, o negócio do gado integra as regiões sulinas ao centro-sul de maneira mais recorrente. Em meados do século XVIII a produção de ouro nas Minas Gerais atingia seu ápice, enquanto que a prata de Potosi, nos domínios espanhóis, escasseava. Com a crise no comércio de mulas para o Alto Peru, o comércio destes animais no Brasil sendo acabou facilitada. Em 1751, Cristóvão Pereira inicia uma fase de reconhecimento da 
região central do que é hoje o Rio Grande do Sul, fundando povoados entre os rios Pardo e Jacuí, formando a base de expedições de preia de gado nos subsequentes cinquenta anos (MENZ, 2009, p. 41).

Mas o fato é que, devido à valorização do gado vacum, principalmente para exportação, as regiões da América Espanhola deixam a criação de muares destinadas ao mercado interno e se voltam para as exportações pelo Atlântico. Com a quebra das minas no Alto Peru, as mulas passaram a ser desnecessárias para o transporte de prata. No Brasil, as mulas começaram a se fazer necessárias na urgência pelo transporte de minérios das Minas Gerais, principalmente o ouro, mas mesmo com o esvaziamento das minas, as mulas não pararam de ser exportadas para o centro-sul. Pelo contrário, a produção aumentou até meados do século XIX, com o Rio Grande do Sul tendo a maior parcela na exportação.

\section{Mulas em movimento: a passagem das tropas de João da Silva Machado pelo Registro de Curitiba, década de 1820}

A atividade de compra e venda de animais era uma das mais lucrativas no Brasil, representando lucros enormes. Assim, este artigo passa a analisar a passagem de animais por João da Silva Machado através do principal pedágio do Caminho do Viamão, procurando jogar um pouco de luz sobre o negócio de animais no sul do continente americano.

João da Silva Machado cresceu neste contexto que acabamos de ver, de aumento de produção de muares para abastecer o centro sul brasileiro e, ao mesmo tempo, de "saída" da América Espanhola do negócio de animais em pé. Inicialmente, Machado atuou como condutor de tropas, passando a desempenhar o papel de negociante, operando em diversas fases do comércio de animais, desde a criação no Rio Grande do Sul até a venda final na feira anual de Sorocaba. Em 1809, temos notícia de sua primeira passagem de tropas pelo registro de Curitiba. A tropa estava distribuída em 132 reses (gado vacum), 39 mulas, 41 cavalos e 4 éguas e chega à Sorocaba 
em janeiro de 1810. Estas são as primeiras notícias de uma tropa particular dele ${ }^{2}$.

Suas sociedades com indivíduos poderosos economicamente, como Antonio da Silva Prado e David dos Santos Pacheco, tornou possível uma grande movimentação de animais, principalmente de muares, tornando Machado o maior negociante de animais do Brasil na primeira metade do século XIX.

Como estudo de caso, analisa-se sua atuação na década de 1820, ponto nevrálgico em sua atividade como comerciante, uma vez que o coloca de vez no mapa dos grandes negociantes do sul. A fonte que ora serve para apreendermos o negócio de animais, como já comentado, são os Livros da Barreira de Curitiba. Deve-se levar em consideração que, em 1829 a Barreira de Curitiba funcionava às margens do rio Iguaçu, em Vila Nova do Príncipe, sendo a partir desta data, transferida para o Rio Negro, onde funcionou até 8 de dezembro de 1853 (LAVALLE, 1974, p. 2).

Os registros serviam como meios de arrecadação vindos a se tornar no século XIX o principal meio de enriquecimento provincial. A forma de pagamento dos registros se dava pela emissão de guias nestes registros, que deveriam ser pagas dentro de 6 a 12 meses no registro de Sorocaba. Estas guias eram passadas em nome do proprietário da tropa e às vezes traziam também o nome do fiador. A dificuldade de carregar a enorme quantidade de dinheiro para saldar os impostos devidos fez com que se criasse essa forma de pagamento, com impostos sendo saldados em Sorocaba. Sorocaba era muitas vezes o final da viagem, onde eram revendidos os animais. Mas antes mesmo de vender os animais, os negociantes deviam saldar os direitos devidos, já que o registro se localizava na entrada da vila de Sorocaba (BADDINI, 2002, p. 73).

Três figuras eram importantes nos registros: o proprietário, o condutor e o fiador. Raras vezes as três eram a mesma pessoa, podendo um indivíduo ter desempenhado as três posições ao longo de sua carreira. João da Silva Machado atuou como condutor, proprietário, e já no auge de sua trajetória, como negociante. Na década de 1820, Machado não necessitava de fiador, demonstrando seu prestígio nos registros, uma vez que somente pessoas que comprovadamente 
possuíam condições de saldar os direitos devidos podiam passar sem fiador. Algumas vezes, mesmo durante o auge da atividade de Machado, seus sócios bancavam os impostos, como foi o caso de Antonio da Silva Prado em duas ocasiões (DAESP, 1826, 1828).

As praças dos Registros no sul da capitania/província de São Paulo acabaram se tornando centros de fiadores e negociantes de animais. A intenção do Registro de Curitiba, por exemplo, foi frustrada, pois os fiadores ali eram também devedores, como negociantes de animais. Em Rio Negro, o principal fiador, Manoel Antonio da Cunha, fazia parte da elite local e desempenhava a função de fiador de forma semi-profissional, vista a grande quantidade de tropas afiançadas por ele (SUPRINYAK, 2006, p. 106).

Antes de passar para a análise das tropas conduzidas por João da Silva Machado, devem-se esclarecer os termos utilizados neste texto. Na documentação geralmente aparecem termos como "negociantes", "aquele que vive de negócios" ou "negociante de tropas". $\mathrm{Na}$ correspondência trocada entre autoridades locais e o presidente da província de São Paulo o termo tropeiro aparece referente àqueles que conduziam as tropas ${ }^{3}$. João da Silva Machado iniciou sua trajetória no negócio de animais como tropeiro (BIBLIOTECA NACIONAL, -II-35,25,05), conduzindo tropas até Sorocaba, mas sua maior atuação se dava no ramo da negociação, organizando as tropas, os locais de compra e venda e os parceiros. Aparentemente, vários tropeiros ascendiam a negociantes e deixavam de realizar as atividades de condução. Entretanto, alguns, mesmo após enriquecer, continuavam a desempenhar esta função. É o exemplo do sócio e afilhado de Machado, David dos Santos Pacheco. Assim, no contexto do Sul, negociante de animais seria o indivíduo que investe o dinheiro e/ou o conhecimento num empreendimento e tropeiro seria o condutor das tropas.

Com relação ao movimento das tropas de muares no sul do Brasil, para o período de 1824 a 1829, havia resquício da relação com a América espanhola no negócio de animais. O gráfico seguinte mostra a variação da movimentação de animais nas viagens de Machado. 
Gráfico 1 - Quantidade de animais passados pelos Registros de Curitiba e Rio Negro por João da Silva Machado - 1824-1829

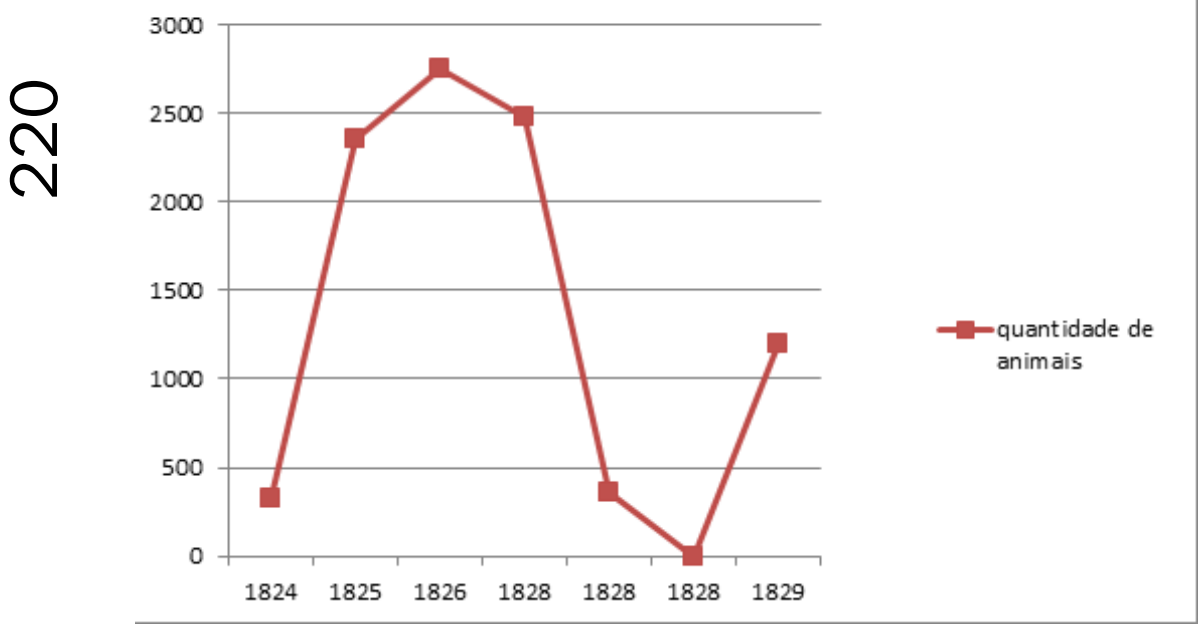

Fonte: APESP. Livros de Barreiras - Rio Negro. $1^{1} \underline{\underline{a}}$ Livro, anos 1826-1836, caixa 252, ordem 1958.

Nestes seis anos foram sete viagens de Machado, com um total de 10.073 animais, sendo 9.476 mulas. Duas dessas viagens contaram com quantidades surpreendentes de animais. Relacionando-se somente as mulas, Machado conduziu um maior número deles em viagens anteriores a 1829. Na viagem de 28 de outubro de 1825 , Machado conduziu 2.354 mulas, além de 37 cavalos e 12 éguas. Em 1826, em sua maior empresa, transportou 2.759 mulas, 45 cavalos e 10 éguas pelo Registro de Curitiba, um total impressionante de 2814 animais. Um enorme esforço e planejamento foram exigidos para conduzir tantos animais; nesta viagem alguns arranjos foram feitos por Antonio da Silva Prado, a partir de São Paulo, a começar pelo pagamento dos direitos do registro de Curitiba.

A primeira coisa que pode se perceber no gráfico é a alta de 1825. Isso se deve ao fato de que Antonio da Silva Prado e Machado, que estavam em sociedade, procuravam, estrategicamente, comprar animais em épocas de conflitos uma vez que estes tendiam a estar 
mais valorizados nesses momentos. Por esta época, especificamente a partir de 1825, os ânimos começam a se acirrar na fronteira Sul. Após a derrota de Artigas para os brasileiros, em 1820, a velha insatisfação contra a invasão dos portugueses se faz sentir novamente em 1825, agora através de um grupo liderado por um ex-oficial de Artigas, Juan Antonio Lavalleja (RECKZIEGEL, 2000, p. 3). Os "trinta e três orientais" declararam a incorporação da Província Cisplatina, que estava sob poder do Brasil, às Províncias Unidas do Rio da Prata. O Brasil por sua vez, declarou a guerra. Assim,

[...] a guerra e a agitação provada pelo movimento de tropas brasileiras e uruguaias desorganizaram todo o sistema econômico do Rio Grande do Sul. O recrutamento e a necessidade de animais para o exercito ocasionaram profundas repercussões em todo o Sul do país, diminuindo sensivelmente o afluxo de muares a Sorocaba [...]. A pequena oferta e a contínua procura de bestas tiveram como conseqüência a alta de preço, que se fez sentir nessa época, na feira de Sorocaba (PETRONE, 1976, p. 108).

Já pressentindo a diminuição dos animais vindos do Rio Grande e o aumento dos preços em Sorocaba, Prado e Machado procuraram comprar o máximo possível de animais no Sul. Daí decorreram estas duas grandes viagens em 1825 e 1826. Apesar de uma desorganização do negócio, os sócios conseguiram sobrepujar estes problemas e obter uma taxa de lucro maior.

Como demonstrado no quadro a seguir, os muares eram vendidos de $26 \$ 000$ (26 mil réis) a $28 \$ 000$ a unidade em Sorocaba, por esta época. Um aumento considerável, entre $140 \%$ e $185 \%$, desde 1822 , quando aparecem as primeiras notícias de preços de muares nas cartas de Prado. A viagem de 1826, em que Machado dirigiu 2.759 mulas para Sorocaba, o capital gerado pode ter se aproximado de 71:735\$, se assumirmos a menor cotação para a feira de 1827 e sem subtrair as despesas. Se, como conjectura Petrone, podemos considerar um lucro mínimo de $30 \%$, os sócios teriam lucrado 21:520\$500 nesta tropa única. 
Mulas em movimento: o mercado interno...

n

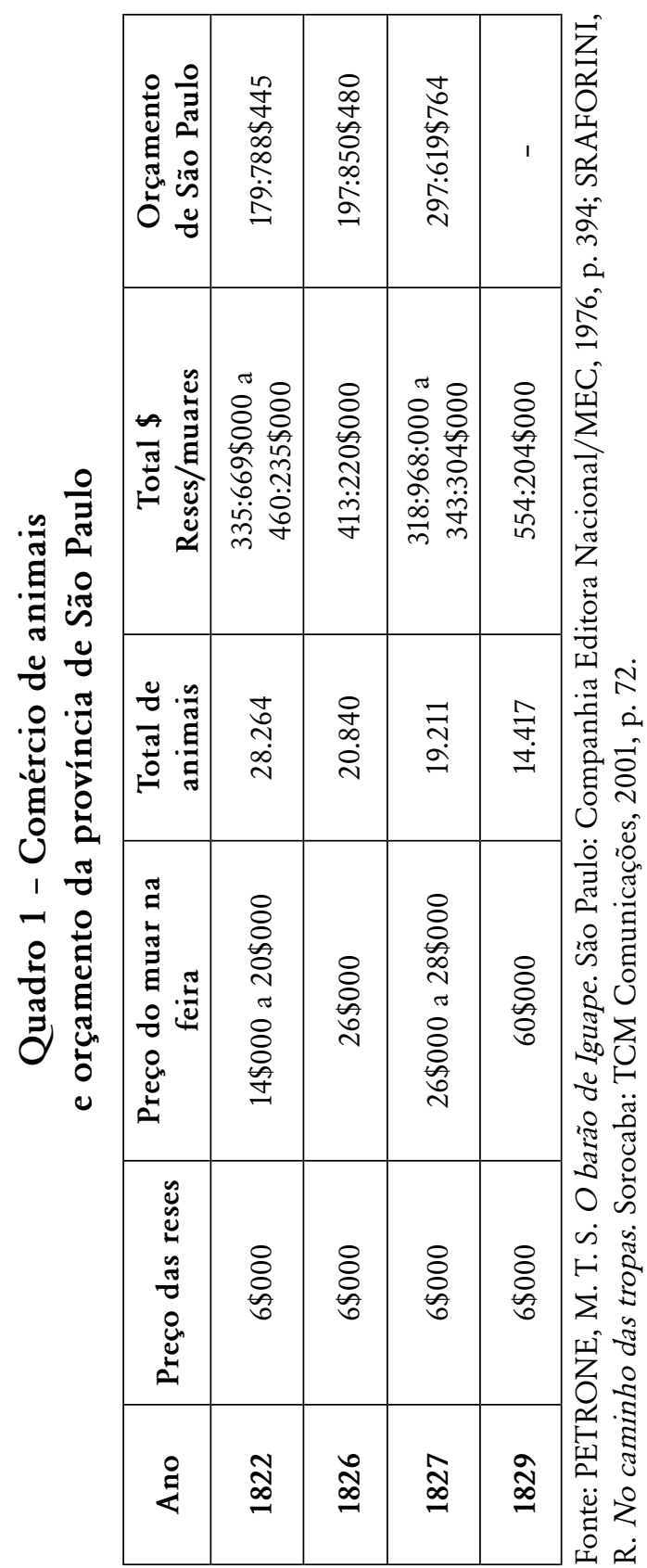

Anos 90, Porto Alegre, v. 23, n. 44, p. 207-230, dez. 2016 
Este quadro acima apresenta valores de muares na conjuntura de guerra na fronteira sul, portanto, um período de desestabilização do mercado de animais, daí a razão da incrível alta dos preços, com uma diminuição na oferta de animais e seu consequente aumento de 428\% no período de 1822 a 1829.

Neste período, Machado conseguiu articular quatro viagens, conduzindo 4514 animais, compostos por 4038 mulas, 255 cavalos e 221 "éguas colônias", que teriam vindo da Colônia de Sacramento. Em 1829, já com o fim dos conflitos, mas ainda sofrendo com as consequências da guerra, as bestas chegaram a ser vendidas por $63 \$ 000 \mathrm{em}$ Sorocaba (PETRONE, 1976, p. 31).

Três das viagens de Machado foram apoiadas por sócios diferentes, que pagaram os impostos de passagem. Foram 3:063\$400 em impostos, algo nada desprezível. Entretanto, a viagem de 1829 parece ter sido toda paga por Machado.

Muitos negociantes passaram "éguas colônias" pelo Registro de Curitiba na década de 1820. Tratava-se de animais criados na Colônia do Sacramento, evidenciando uma produção ainda resistente nesta região. Aparentemente, com a pacificação de Montevidéu após a revolta artiguista ${ }^{4}$, o comércio se reiniciou com o Uruguai. Entre os anos de 1824 e 1829, João da Silva Machado trouxe 231 éguas provenientes de Colônia, 185 somente em fevereiro de 1828 para Joaquim Mariano Galvão, paulista, que no início do século XIX atuara em posições de destaques na fronteira com o Uruguai e, portanto, conhecia bem a qualidade dos animais da região (BORREGO, 2010, p. 23). Pelas técnicas empregadas e pela necessidade de animais mais resistentes devido às viagens por caminhos bastante acidentados, as éguas criadas no lado espanhol deviam ser mais resistentes. A opção por estes animais também pode revelar o seu destino para o acasalamento e geração de muares nas proximidades do centro distribuidor de Sorocaba, já que as éguas não possuíam a força de carga que seu parente híbrido possuía.

Após esse período de intensas atividades, Machado se retirou do negócio até 1834 e não encontramos mais tropas conduzidas em seu nome. Neste período, entre 1830 e 1833, Machado foi membro do Conselho Geral da Presidência de São Paulo (OLIVEIRA, 2009, p. 187), o que talvez tenha exigido sua presença na capital da 
província. Anteriormente, ele não possuía cargos políticos importantes, atuando mais ativamente em cargos nas Ordenanças, o que possibilitava certa flexibilização de movimento.

Essa prática de, após enriquecimento, se retirar parcialmente dos negócios privados para atuar na política não era uma prática original no Brasil nem mesmo na América Espanhola. Francisco Candiotti, além de ser grande negociante de animais, foi também importante estancieiro e político de prestígio (BARSKY; DJENDEREDJIAN, 2003, p. 154).

A trajetória de Francisco Candioti é muito interessante para efeitos de comparação com a do nosso negociante, João da Silva Machado. De maneira muito semelhante, ambos ascenderam socialmente através do negócio de mulas até chegar a importantes cargos políticos no interior da estrutura administrativa dos seus Estados em formação. Machado, além de vários outros cargos formidáveis, chegou ao cargo de Senador, em 1853, um dos mais altos na estrutura política brasileira de meados do século XIX. Candioti, no final do século XVIII e início do XIX, conduzia uma caravana anual de 5000 a 6000 mulas à região do Alto Peru. Além disso, foi governador de Santa Fé e apoiou Artigas e a Independência de Buenos Aires (TEDESCHI, 2005). Mas nenhum dos dois se afastou permanentemente das atividades que os fizeram enriquecer.

\section{Considerações finais}

Como mostrei acima, João da Silva Machado algumas vezes comprava animais diretamente em regiões como Buenos Aires e Montevidéu. Além disso, ele, assim como seu sócio, David dos Santos Pacheco, possuía profundos contatos com a elite do Rio Grande do Sul e de outras regiões ligadas ao negócio de animais. A feira de Sorocaba, que redistribuía os animais vindos de regiões do cone-sul como Buenos Aires, Montevidéu e Rio Grande do Sul, aponta para um mercado interno fortemente interligado entre essas 
áreas. Interligações essas exercidas por extensas redes de relações econômicas e familiares. Como demonstram Tiago Gil (2009) e Carlos Supriniak (2006), atores do negócio de animais, tais como Machado e Pacheco possuíam laços de parentesco e de negócios que percorriam toda a extensão do caminho do Viamão, interligando os diversos nódulos do mercado de animais.

Estes casos, dentre numerosos outros, demonstram a possibilidade de ascensão através da atividade de criação e venda de mulas que foi bastante marcante nestas paragens meridionais da América. A possibilidade de enriquecimento através deste negócio ainda está por ser melhor analisada, principalmente através de metodologias caras à História Econômica e fontes quantitativas, já que as possibilidades de lucro eram imensas. A dificuldade reside nas fontes, nos valores e nos processos de compra e venda, já que o negócio de animais era por demais difuso, tanto temporal quanto geograficamente, não possuindo a riqueza documental que outras atividades possuem. Além disso, a amplitude inflacionária do Brasil e da América espanhola era enorme, o que faz com que os valores diferissem muito em questão de meses.

Inventários post-mortem, por exemplo, fontes muito ricas em valores, são complicadíssimas para se estudar este negócio. Dependendo da localidade, ou do momento da morte do inventariado, os valores diferiam muito. Algumas vezes, encontram-se casos de reconhecidos negociantes de muares, que não possuíam estes animais relacionados em seus inventários, devido a uma possível venda longo antes da morte. De qualquer forma, o presente estudo apontou as relações entre as diferentes regiões do cone-sul e as possibilidades de enriquecimento com o negócio de animais.

O que deve ser pensado para o futuro com relação a este tipo de trabalho, é um diálogo mais evidente entre as historiografias do cone-sul além de um trabalho comparativo utilizando fontes primárias de ambos os lados da América do sul, o que pode revelar uma maior relação econômica entre os dois lados das Américas sob domínio ibérico. 


\section{MULES IN TRAFFIC: THE BRAZILIAN INTERNAL MARKET AND THE MULETEER BUSINESS IN THE FIRST HALF OF THE 19TH CENTURY}

Abstract: The objective of this work is to analyze the Brazilian mule business and how did it connect with the regions of Hispanic America. In that intention, I study the trajectory of one of the largest mule dealers in nineteenth century Southern Brazil, João da Silva Machado. This individual endeavoured several trips to the Gaucho Pampas in Buenos Aires and Montevideo, seeking to buy the best animals to be resold at a fair in São Paulo. Thus, I analyze the relationship of the internal market that stretched from Spanish side to the Brazilian - in the economic space linking these two markets through mule business. For this, I use the Registros de Passagem de Animais do Registro de Curitiba, between the years 1824 and 1829, important point in the ascension of the internal animal market. This registers, that were used as a tolls, brought listed all animals that passed thought that location and their origin. Thus, a great source to apprehend the flow of the animal business in the south and, including, its relation with the Spanish side.

Keywords: Mule business. Internal market. Transportation.

\section{Notas}

${ }^{1}$ Tipos de animais que apareciam nos inventários post-mortem e nos mapas de animais nas regiões do sul: muar (animais de transporte de cargas (mulas, machos, éguas e bestas), cavalar (para locomoção, transporte de pessoas e reprodução), vaccum (vacas, bois, touros e novilhos), lanígero (carneiros e ovelhas) e suíno. Ver Borges (2010); Osório (2007).

${ }^{2}$ Em documentação do registro de Curitiba, de 1809, Machado passa como tropeiro. Biblioteca Nacional -II-35,25,05. (Agradeço a Tiago Gil pela disponibilização destes dados).

${ }^{3}$ Principalmente DAESP, ofícios diversos.

${ }^{4} \mathrm{Em} 1815$, Artigas se apodera de Montevidéu, instalando um governo revolucionário, procurando a independência da região do Prata. Os conflitos duraram até 1820. 


\section{Referências}

ALBORNOZ, Cristina López. Tempos de cambio: produccion y comercio em Tucuman (1770-1820). Andes, Salta, n. 13, p. 213-248, 2002.

ASSADOURIAN, Carlos Sempat. El sistema de la economia colonial: mercado interno, regiones e espacio econômico. Lima: Instituto de Estúdios Peruanos, 1982. AZARA, Félix de. Descripción general del Paraguay. Madrid: Alianza Editorial, 1990.

BADDINI, Cassia Maria. Sorocaba no Império: comércio de animais e desenvolvimento urbano. São Paulo: Fapesp; Annablume, 2002.

BALHANA, A. P.; PINHEIRO MACHADO, B.; WESTPHALEN, C. História do Paraná. v. 1. Curitiba: Grafipar, 1969.

BARSKY, Osvaldo; DJENDEREDJIAN, Julio. Historia del capitalismo agrário pampeano: La expansión ganadera hasta 1895. v. 1. Buenos Aires: Siglo XXI Editores Argentina, 2003.

BARMAN, Roderick J. Packing in british Columbia: transport on a resource frontier. Journal of Transport History, Manchester, n. 21, p. 140-167, 2000.

BARRIOS PINTO, Antonio. Historia de la ganaderia em el Uruguay. Montevideo: Biblioteca Nacional, 1971.

BLASI, Antônio Luiz. Tropeirismo, registro e poder. 2004. Monografia (Graduação em História)-Universidade Federal de Santa Catarina, Florianópolis, 2004.

BORGES, Luiz Adriano G. Tropeirismo e criação de animais em São José dos Pinhais, Paraná, segunda metade do século XIX. In: ENCONTRO DE PÓS-GRADUAÇÃO EM HISTÓRIA ECONÔMICA E III CONFERÊNCIA INTERNACIONAL DE HISTÓRIA DE ECONÔMICA, 5., 2010, Brasília, DF. Anais... Brasília, DF: UnB, 2010.

BORGES, Nilsen C. Oliveira. Terra, gado e trabalho: sociedade e economia escravista em Lages, SC (1840-1865). 2005. Dissertação (Mestrado em História)-Universidade Federal de Santa Catarina, Florianópolis, 2005.

BORREGO, Maria Aparecida de Menezes. Laços familiares e aspectos materiais da dinâmica mercantil na cidade de São Paulo (séculos XVIII e XIX). Anais do Museu Paulista, São Paulo, v. 18, n. 1, p. 11-41, jan./jun., 2010.

CATELLI JR., Roberto. Poder local - consolidação e revolta: Sorocaba, 1823/1842. 1993. Dissertação (Mestrado em História)-Universidade de São Paulo, São Paulo, 1993.

Anos 90, Porto Alegre, v. 23, n. 44, p. 207-230, dez. 2016 
CHEDA, Raúl D. El corredor oriental y la jurisdicción Montevideo - un aspecto de la capitulación Mendoza y la jurisdicción Montevideo: ocupación territorial y corredores comerciales (1535-1789). In: PRIMEIRAS JORNADAS DE ECONOMIA REGIONAL COMPARADA, 2005, Porto Alegre. Anais... Porto Alegre: FEE, 2005.

CHRISTILLINO, Cristiano Luis. Litígios ao sul do império: a lei de terras e a consolidação política da coroa no Rio Grande do Sul (1850-1880). 2010. Tese (Doutorado em História)-Universidade Federal Fluminense, Niterói, 2010.

CONTI, Viviana; SICA, Gabriela. Arrieros andinos de la colonia a la independência. Nuevo Mundo Mundos Nuevos, Paris, 31 jan. 2011. Disponível em: <http://nuevomundo.revues.org/60560>. Acesso em: 18 jul. 2013.

DAESP. Livros da Barreira do Rio Negro, 1824-1852. Livro 1 e 2: anos 18261836, caixa 252, ordem 1958; livro 3 e 4: anos 1837-1840, caixa 255, ordem 1961; livro 5, 6 e 7: anos 1839-1846, caixa 257, ordem 1963. Livro 8: anos 1845-1849, caixa, 258; Livro 9: 1847-1850, caixa 260; livro 10, anos 1850-1854, caixa 261.

DJENDEREDJIAN, Julio Cesar. Fuentes, pobres, métodos complejos: producción agroganadera y sociedad em un área fronteriza del rio de La Plata tardocolonial. Anuario de estúdios Americanos, Sevilla, v. 59, n. 2, p. 463-489, 2002.

GARAVAGLIA, J.C. Pastores y labradores de Buenos Aires: una historia agraria de la campaña bonaerense 1700-1830. Buenos Aires: Ediciones de la Flor, 1999. GELMAN, Jorge. Campesinos y stancieros: una region del Rio de la plata a fines de la época colônia. Buenos Aires: Los Libros del Riel, 1998.

GIL, Tiago Luis. Infiéis transgressores: os contrabandistas da fronteira (1760-1810). 2002. Dissertação (Mestrado em História)-Universidade Federal do Rio de Janeiro, Rio de Janeiro, 2002.

. Coisas do caminho: Tropeiros e negócios do Viamão à Sorocaba (17801810). 2009. Tese (Doutorado em História Social)-Universidade Federal do Rio de Janeiro, Rio de Janeiro, 2009.

GOULART, José Alípio. Tropas e tropeiros na formação do Brasil. Rio de Janeiro: Conquista, 1961.

HAMEISTER, Martha Daisson. O continente do Rio Grande de São Pedro: os homens, suas redes de relações e suas mercadorias semoventes (c.1727-1763). 2002. Dissertação (Mestrado)-Instituto de Filosofia e Ciências Sociais, UFRJ, Rio de Janeiro, 2002.

KLEIN, Herbert S. A oferta de muares no Brasil central: o mercado de Sorocaba, 1825-1880. Estudos Econômicos, São Paulo, v. 19, n. 2, p. 347-372, maio/ago. 1989.

Anos 90, Porto Alegre, v. 23, n. 44, p. 207-230, dez. 2016 
LACOSTE, Pablo. Carretas e transporte terrestre bioceánico. Estudos Ibero-americanos, Porto Alegre, v. 31, n. 1, p. 7-34, jun. 2005.

. El arriero y el transporte terrestre en el cono sur (Mendonza, 1780-1800).

Revista de Indias, Madrid, v. 68, n. 244, p. 35-68, 2008.

LAVALLE, Aida Mansani. Análise quantitativa das tropas passadas no registro do Rio Negro (1830-1854). 1974. Tese (Livre Docência)-Universidade Federal do Paraná, Curitiba, 1974.

LENHARO, Alcir. As tropas da moderação: o abastecimento da Corte na formação política do Brasil, 1802-1842. São Paulo: Símbolo, 1979.

MACHADO, João da Silva. Informações que pude obter do alferes Antonio Pereira Borges, comandante da companhia exploradora em Campos Gerais de Curitiba, na demanda dos campos denominado Paiqueré. Revista do Instituto Histórico e Geográfico (RIHGB), Rio de Janeiro, t. 5, p. 109-117, 1885.

MÁRQUEZ, María Victoria. Grupos de mercaderes cordobeses en el espacio peruano: la incidencia de las reformas borbónicas y las sublevaciones indígenas. In: JORNADAS DE HISTORIA ECONÓMICA, 21., 2008, Caseros. Anais... Caseros: Universidad Tres de Febrero, 2008.

MENZ, Maximiliano M. Entre impérios: formação do Rio Grande na crise do sistema colonial português (1777-1822). São Paulo: Alameda, 2009.

OLIVEIRA, Carlos Eduardo França. Poder local e palavra impressa: dinâmica política em torno dos Conselhos Provinciais e da imprensa periódica em São Paulo, 1824-1834. 2009. Dissertação (Mestrado em História)-Universidade de São Paulo, São Paulo, 2009.

OSORIO, Helen. O império português no sul da América: estancieiros, lavradores e comerciantes. Porto Alegre: UFRGS, 2007.

PAZ, Gustavo L. A la sombra del Perú: mulas, repartos y negócios en el norte argentino a fines de la colônia. Boletin del instituto de historia argentina y americana Dr. Emilio Ravignani, Buenos Aires, s. 3, n. 20, p. 45-68, 2. sem. 1999. PETRONE, Maria Thereza Schorer. O Barão de Iguape: um empresário da época da independência. São Paulo: Companhia Editora Nacional, 1976.

PRIORE, Mary del Priore; VENANCIO, Renato Venâncio. Uma história da vida rural no Brasil. Rio de Janeiro: Ediouro, 2006.

RECKZIEGEL, Ana Luiza Setti. A instalação do Estado Nacional e as tensõesfronteiriças: Uruguai e Rio Grande do Sul no período 1822-1851. In: PRIMEIRAS JORNADAS DE HISTÓRIA REGIONAL COMPARADA, 2000, Porto Alegre. Anais... Porto Alegre, 2000.

Anos 90, Porto Alegre, v. 23, n. 44, p. 207-230, dez. 2016 
ROSAL, Miguel A.; SCHMIT, Roberto. Las exportaciones pecuárias bonaerenses y el espacio mercantil rioplatense (1768-1854). In: FRADKIN, R.; GARAVAGLIA, J. C. En busca de un tiempo perdido: la economía de Buenos Aires en el país de la abundancia 1750-1864. Buenos Aires: Prometeo Libros, 2004, p. 159-193. SIMONSEN, Robert C. História econômica do Brasil: 1500-1820. 4. ed. Brasília, DF: Senado Federal, 2005.

(m) STRAFORINI, Rafael. No caminho das tropas. Sorocaba: TCM Comunicações, N 2001.

SUPRINYAK, Carlos Eduardo. Comércio de animais de carga no Brasil imperial: uma análise quantitativa das tropas negociadas nas províncias do Paraná e São Paulo. 2006. Dissertação (Mestrado)-UNESP, São Paulo, 2006.

TEDESCHI, Sonia. La villa del Paraná y la ciudad de Santa Fe: Vinculos, interacciones e influencias em um área fronteriza (etapa colonial hasta 1824). Porto Alegre: FEE, 2005. Disponível em: <http://cdn.fee.tche.br/jornadas/2/ H4-17.pdf $\gg$. Acesso em: 11 abr. 2016.

TELL, Sonia. Córdoba rural, una sociedad campesina: 1750-1850. Buenos Aires: Prometeo Libros, 2005.

WESTPHALEN, Cecilia. O barão dos campos gerais. Curitiba: CD Editora, 1995

Recebido em: 25/05/2016 Aprovado em: 20/08/2016 